\title{
Erratum to: TXT-tool 4.039-3.2 \\ How to Assess Landslide Activity \\ and Intensity with Persistent \\ Scatterer Interferometry (PSI): The PSI-Based Matrix Approach
}

Francesca Cigna, Silvia Bianchini and Nicola Casagli

\section{Erratum to: \\ Chapter "TXT-tool 4.039-3.2 How to Assess Landslide Activity and Intensity with Persistent Scatterer Interferometry (PSI): The PSI-Based Matrix Approach" in: K. Sassa et al. (eds.), Landslide Dynamics: ISDR-ICL Landslide Interactive Teaching Tools, https://doi.org/10.1007/978-3-319-57777-7_29}

The original version of the book was inadvertently published without incorporating the affiliation correction for author "F. Cigna" in chapter "TXT-tool 4.039-3.2 How to Assess Landslide Activity and Intensity with Persistent Scatterer Interferometry (PSI): The PSI-Based Matrix Approach”, which has been now updated as follows:

F. Cigna, S. Bianchini, N. Casagli

Earth Sciences Department, University of Firenze,

Via G. La Pira 4, 50121 Florence, Italy

e-mail: francesca.cigna@asi.it

S. Bianchini

e-mail: silvia.bianchini@unifi.it

N. Casagli

e-mail: nicola.casagli@unifi.it

Present Address:

F. Cigna

Italian Space Agency (ASI), Via del Politecnico snc,

00133 Rome, Italy

The erratum chapter and the book have been updated with the change.

The updated online version of this chapter is available at https://doi.org/10.1007/978-3-319-57777-7_29 